\title{
GLOBAL DISTRIBUTION OF HELIUM IN THE UPPER ATMOSPHERE DURING SOLAR MINIMUM
}

\author{
R. P. CAGLAO and R. B. KERR \\ Space Physics Research Laboratory, Department of Atmospheric and Oceanic Science, \\ University of Michigan, Ann Arbor, MI 48109, U.S.A.
}

(Received in final form 9 April 1984)

\begin{abstract}
Helium in the Earth's thermosphere traces the dynamical systems that redistribute energy and mass. Measurements of the global helium distribution in the thermosphere, using Atmosphere Explorer satellite $C,(A E-C)$, show a gradual seasonal change in the number density of helium for all latitudes. The enhancement in helium over the winter pole (the helium bulge) changes in magnitude slowly as seasons progress. The bulge builds and recedes following the progression of winter North to South and back again. This progression of the winter helium enhancement is presented in this paper using latitudinal profiles of helium number density for each month during the year. The absolute magnitude of the winter helium enhancement in the auroral regions is affected by auroral heating at low altitudes. The reduction in the winter helium bulge at low altitudes shown in $A E$-Cdata can be traced to this localized heating. The gradual variation in helium concentration measured at many latitudes for all seasons of the year implies that global thermospheric wind systems change gradually with the seasons.
\end{abstract}

\section{INTRODUCTION}

In the Earth's thermosphere, differential heating induces contrasts in temperature between summer and winter hemispheres. This leads to a higher pressure in the preferentially heated summer hemisphere, and large scale thermospheric wind systems develop to carry the heat from the warm to the cold hemisphere. As a consequence, helium and other atmospheric gases are carried from the summer to the winter hemisphere. To satisfy flow continuity and mass conservation, this implies a vertical transport upwards over the summer hemisphere, meridional flow from summer to winter hemispheres, a vertical transport downwards over the winter polar region, and return flow at low altitudes (Reber and Hays, 1973). The meridional flow increases in velocity with height due to the atmospheric density decrease with increasing altitude.

Helium, a minor, inert gas embedded in higher molecular weight gases, is dragged along with the major gas flow. Because of its large scale height, more helium is transported to the winter pole than is returned to the summer pole. In addition, there is a vertical diffusion barrier in the lower thermosphere, where molecular nitrogen density is high, preventing the diffusion of helium downward over the winter pole. Thus, a helium concentration enhancement or bulge appears over the winter pole in the thermosphere(Mayr et al., 1978). Because of helium's inertness, large scale height and small temperature dependence, it is an ideal candidate for use as a tracer gas of thermospheric dynamics.
The winter helium bulge was first detected by the atmospheric drag measurements of Explorer satellites 9, 14, 24 and 32 (Keating and Prior, 1968; Reber et al., 1968). Its existence has subsequently been verified by mass spectrometers aboard satellites OGO 6 (Reber et al., 1971), ESRO 4 (von Zahn, 1975), AE-C (Mauersberger et al., 1976a) and $A E-\mathrm{D}$ (Mauersberger et al, 1976b). Although the existence of the winter helium bulge has been clearly demonstrated, to our knowledge there have been no reported measurements showing the time evolution of the winter helium enhancement over an entire year.

This paper presents the annual variation of the concentration of helium in the Earth's atmosphere measured in situ by the closed source Neutral Atmosphere Temperature Experiment mass spectrometer, NATE (Spencer et al., 1973b), or the Open Source mass Spectrometer, OSS (Nier et al., 1973), on board the Atmosphere Explorer $\mathrm{C}(A E-\mathrm{C})$ satellite (Dalgarno et al., 1973; Spencer et al., 1973a). The observations were made during the solar minimum period centered on 1976 when geomagneticactivity was also low. The results of the measurements of a monthly variation in helium number density show a smooth latitudinal redistribution of helium through the year. This implies the thermospheric winds forcing helium redistribution vary slowly with time.

\section{DATA ANALYSIS}

Data were obtained from the Unified Abstract Files, which are a summary of the Atmosphere Explorer data 
base and are available at the University of Michigan. These files consist of measurements of geophysical parameters derived from data transmitted by the $A E-\mathrm{C}$ spacecraft. These data are filtered, averaged every $15 \mathrm{~s}$, and tabulated by the principal investigators for each instrument. OSS and NATE measurements of helium number densities made from December 1974 to August 1977 were considered in this study. During this period, $A E-\mathrm{C}$ (orbital inclination $68.1^{\circ}$ ) was in the circular phase of its orbit and the solar cycle passed through a minimum.

In order to present the helium latitudinal profile for a particular month, we chose to consider measurements made during an 11-day period centered on the 21 st of that month. Because the data were to be averaged over the 11-day period, it was necessary to screen for observations made when conditions might weight the average on a particular day. In other words, we sought the mean, average daily concentration of helium for each of the 11 days used in each month's data sample. Earlier studies of the winter helium enhancement (von Zahn, 1975; Mauersberger et al., 1976a; Mayr et al., 1978) have been difficult to compare one with another because of differences in local solar time, geomagnetic activity, and spacecraft altitude. It was the variability in the $A E-C$ data set due to these factors that we sought to reduce.

We noted in the work of Newton et al. (1975) using the Neutral Atmospheric Composition Experiment (NACF) aboard the San Marco 3 satellite, Reber's (1976) analysis of OGO-6 data (see Fig. 5 of that paper), and data collected using the Atmospheric Explorer E (AE-E) satellite's NACE(see Fig. 1) that there existed an asymmetric diurnal bulge in the helium number density. In this bulge, situated in local solar time (L.S.T.) between 04.00 and 14.00 as shown in Fig. 1, the helium number density deviates from the mean value for the entire data set more than any other portion of the data. To reduce this variation from the mean daily average and produce a less noisy data set while retaining sufficient data for meaningful monthly averages, we chose to eliminate all data in the $04.00-14.00$ L.S.T. range from the final monthly average data set. The result of a sample run when excluding the data between 04.00 and 14.00 as opposed to a data set containing these values, was a $31 \%$ reduction of the standard deviation (S.D.) of the total data set about the daily mean helium number density value. Eliminating other L.S.T. ranges did not reduce the S.D. of the data as much.

Measurements during periods of anomalously high geomagnetic activity, relative to the nominal solar minimum conditions, would also unfairly weight the mean average daily helium concentrations. As von

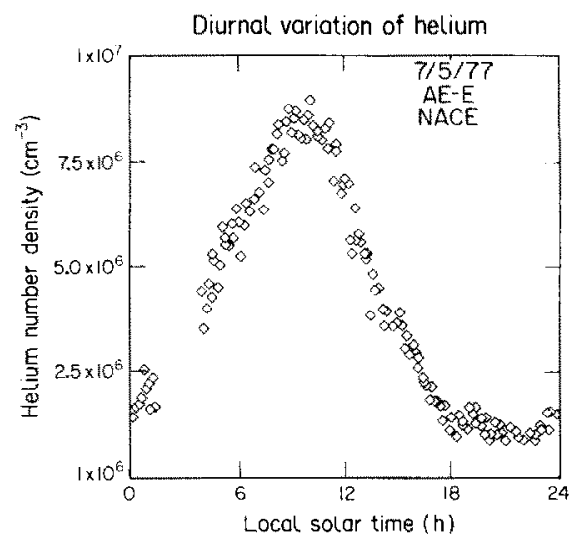

Fig. 1. THE VARIATION IN Helum NUMBer DeNSITY WITH RESPECT TO LOCAL SOLAR TIME:

The largest helium number densities were detected near 09.00 L.S.T., with the bulk of the peak occurring between 04.00 and 14.00. Data are from $A E-E$ NACE (Pelz et al., 1973). Helium number densities were measured on a single orbital pass.

Latitude $20^{\circ} \mathrm{S}$ to $20^{\circ} \mathrm{N} ; \mathrm{F} 10.7=87 ;$ Alt. $=270 \mathrm{~km}$.

Zahn (1975) and Jacchia et al. (1976) have shown, during periods of high geomagnetic activity there is a decrease in helium concentration in the geomagnetic polar regions. With this in mind, we discarded all observations made when the geomagnetic index, $K_{p}$, exceeded $4+$, since such observations represent sporadic increases in geomagnetic activity in the solar minimum data set and possibly sporadic changes in the helium concentration.

In order to remove the effects of varying satellite altitude, each of the remaining helium number density measurements were normalized to $275 \mathrm{~km}$ assuming a diffusive equilibrium profile. The temperatures needed for determination of the helium scale height of each data point were generated by the MSIS atmospheric model (Hedin et al., 1977). The data during the period of interest were taken from an altitude range of 250 $300 \mathrm{~km}$. Hence, the normalization is an interpolation over approx. $10 \%$ of the helium scale height (roughly $200 \mathrm{~km}$ ) in all cases.

For each month being considered, the helium densitics, after passing the above filters and adjustments, were sorted into latitude bins of two degree widths, summed and averaged.

The result of the above manipulations is an 11-day average, for each month of the year, of average helium number densities for an altitude of $275 \mathrm{~km}$ and at latitudes ranging from $68^{\circ}$ North to $68^{\circ}$ South. The effects of L.S.T. were reduced by eliminating data in certain I.S.T. ranges, the effects of geomagnetic activity were limited by elimination of sporadically large geomagnetic events, and altitude variations were 
Monthly helium number density variation with lotitude ot $275 \mathrm{~km}$
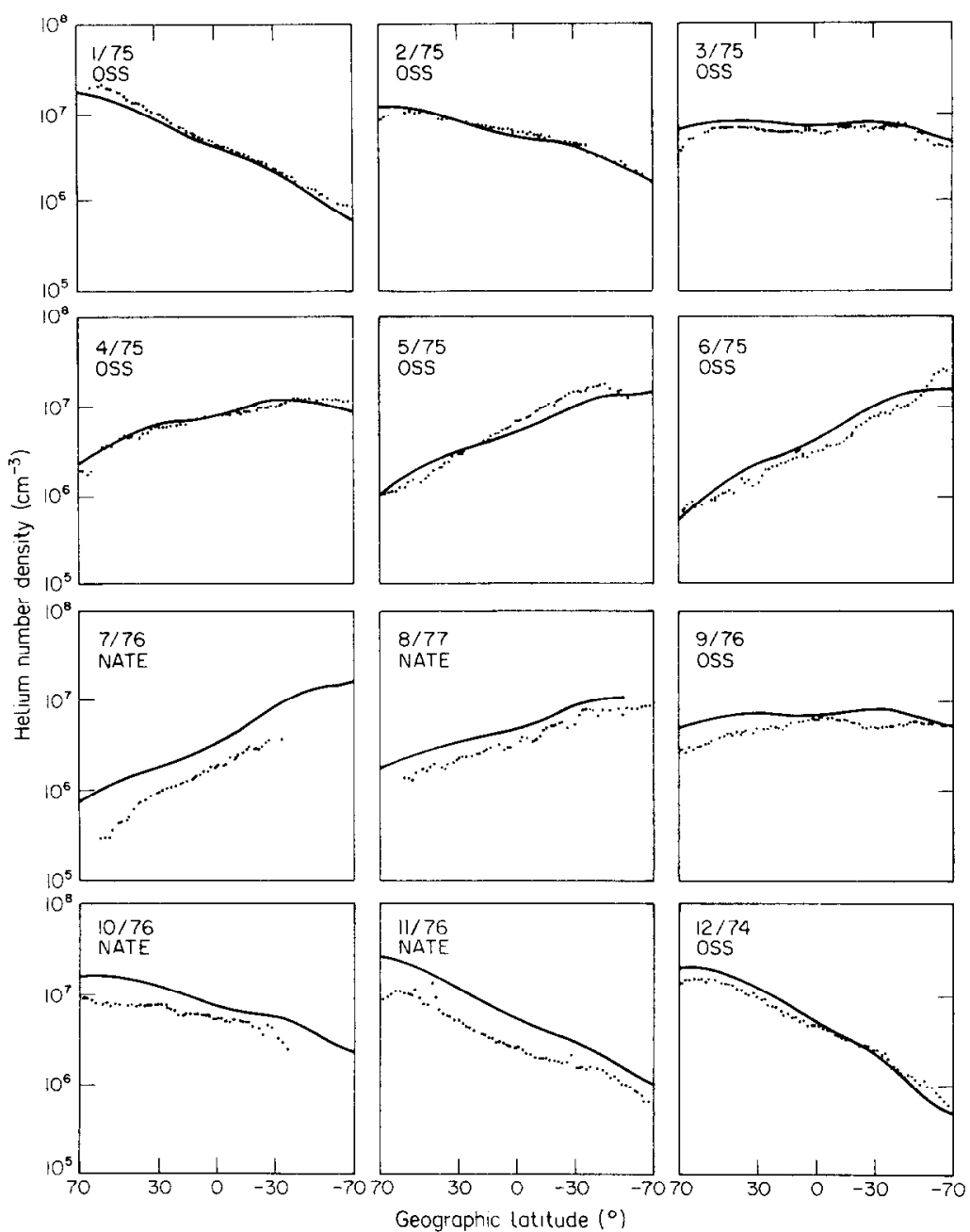

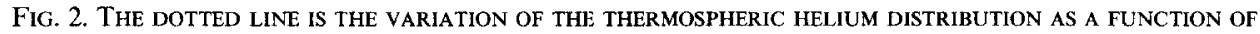
GEOGRAPHIC LATITUDE DURING THE YEAR NEAR SOLAR MINIMUM AS MEASURED BY $A E-C$.

For a particular month each data point represents an 11-day average of densities measured from the 16 th to the 26th at a given latitude. The effects of L.S.T., geomagnetic activity, and altitude were reduced (see text). There is a slow redistribution of helium throughout the year. Measurements are from $A E-C$ OSS or NATE. L.S.T. $00.00-04.00$ and 14.00-24.00; F10.7: January $=75.4$, February $=70.7$, March $=72.1$, April $=68.5$, May $=67.6$, June $=68.5$, July $=67.3$, August $=86.7$, September $=72.5$, October $=77.1$, November $=75.5$, December $=86.8 ;$ Alt $=275 \mathrm{~km}$. The solid lines are the results obtained by running the MSIS -83 thermospheric model (Hedin, 1983) for the same conditions.

normalized out of the data set. A plot of helium number densities vs latitude for the 12 selected months is shown in Fig. 2 (see data points).

The solid line in Fig. 2 represents the results from a run, for the 21 st of each month, of the MSIS-83 (Hedin, 1983) thermospheric model. The model was run at $275 \mathrm{~km}$ using the same L.S.T.s, F10.7 and $K_{p}$ values as those in the $A E-C$ data. Agreement is particularly good for months in 1974 and 1975. However, marked differences between $A E-C$ measurements and MSIS-83 model values can be noted for data from months in 1976 and 1977.

The analysis procedure for the $A E-C$ data (noted above) yielded good reproducibility of monthly helium 
Helium profile consistency of

2 years near solar minimum
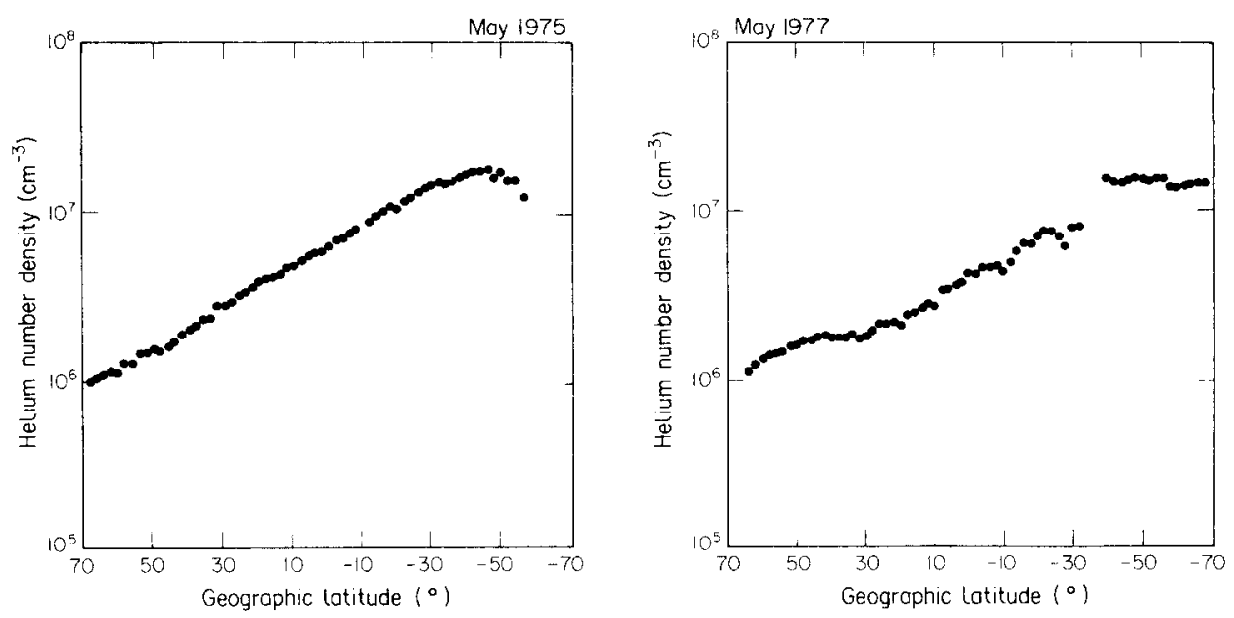

FIG. 3. TWO PLUIS DEMONSIKA IING THE CONSISTENCY OF THE MONTHLY HELIUM LATITUDE PROFILE FOR 2 YEARS NEAR THE 1976 SOLAR MINIMUM.

The raw $A E$-C data were reduced in the same manner as were those in Fig. 2. The profile for any month should be similar for years with comparable solar activity as indicated by these plots. The May 1975 data is from OSS, F10.7 = 67.6. The May 1977 data is from NATE, F10.7 = 81. For both months, L.S.T. was $00.00-04.00$ and $14.00-24.00$, Alt. $275 \mathrm{~km}$.

concentration vs latitude profiles from year to year for solar minimum conditions as evidenced by Fig. 3.

The differences between the OSS and NATE instruments, which made the helium concentration measurements, were considered. One or the other instrument was used, depending on availability of data, to determine the helium distribution with latitude during a particular month. We recognize that the OSS instrument bears an ideal, closed source accommodation coefficient for helium of less than unity (Trinks et al., 1977). Nevertheless, both instruments measure nearly the same absolute magnitudes of helium concentrations as shown in Fig. 4. Thus, either instrument was used in the presentation of the helium enhancement shown in Fig. 2.

In addition, to investigate the altitude dependence of the latitudinal distribution of helium in the thermosphere, the Atmosphere Explorer D ( $A E$-D) satellite (orbital inclination 90.2 degrees) measurements were used. $A E-\mathrm{D}$ data were selected from December 1975 and January 1976 at a time of low to moderate geomagnetic activity $\left(A_{p} \bumpeq 15.0\right)$ and low solar activity $(\mathrm{F} 10.7 \bumpeq 75)$. Contours of helium were plotted vs latitude and altitude, and are shown in Fig. 5.

\section{DISCUSSION}

The most prominent feature in Fig. 2 is the leisurely progression, building and receding, of the helium bulge from North to South as the year progresses. Since the distribution of helium in the thermosphere can be linked to dynamics, as indicated above, this implies that winds in the thermosphere vary slowly through the year. The winds flow from the summer to the winter

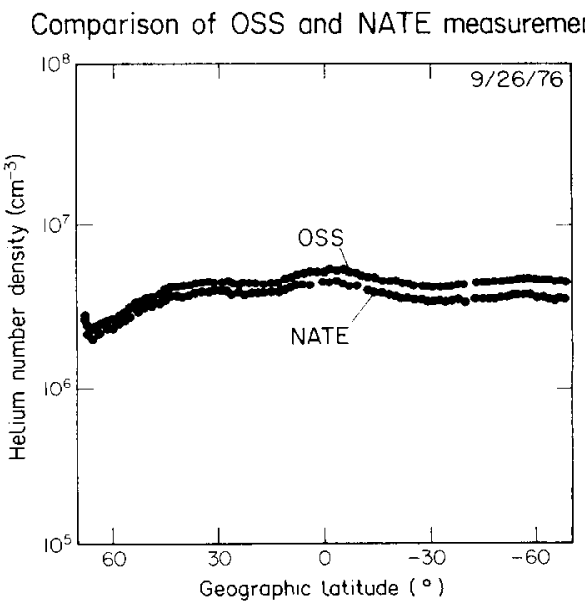

Fig. 4. A COMPARISON OF HELIUM MEASUREMENTS MADE BY NATE AND OSS DURING A SINGLE ORBIT OF AE-C.

Good agreement between OSS and NATE measurements is typical of this and other plotted data sets. $\mathrm{F} 10.7=70$, L.S.T. $=16.70-04.50$, Alt. $=300 \mathrm{~km}$. 


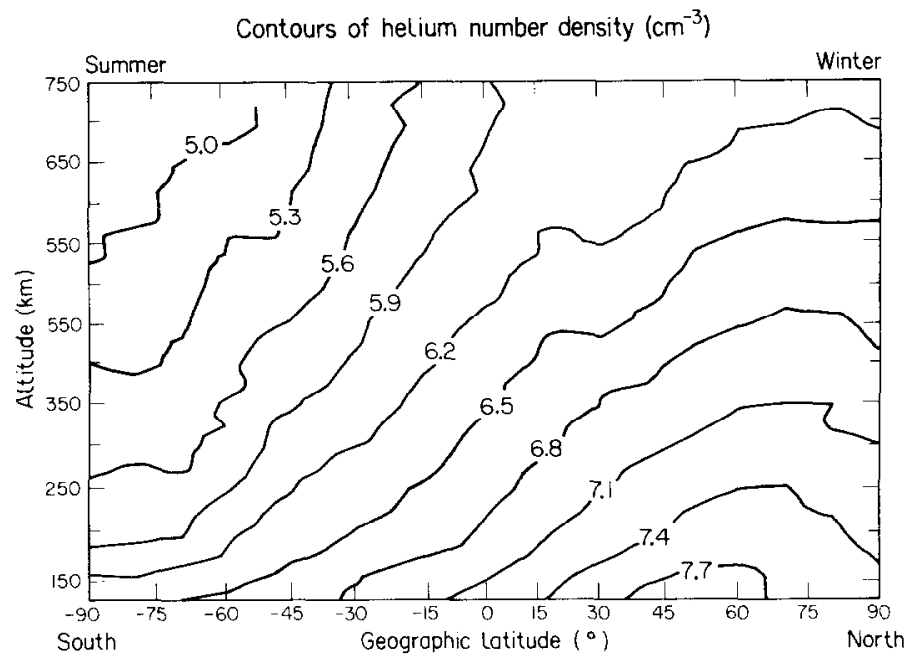

Fig. 5. Contours of HELIUM NUMBER DENSITY AS A FUnCtION OF ALTITUDE AND GEOGRAPHiC LATITUDE AS MEASURED BY THE OSS EXPERIMENT ABOARD $A E$-D.

The observations were accumulated and are averaged over the period I December 1975 to 27 January 1976. Depression in the helium number density at low altitudes near the North Pole $\left(+90^{\circ}\right)$ may indicate upwelling due to auroral heating. $F 10.7=70-80$, L.S.T. $=09.50-05.40$. Contour numbers are log scale (e.g. $5.0=10^{5} \mathrm{~cm}^{-3}$ ).

hemisphere, reach their greatest magnitude at the solstice, decrease towards equinox, reverse in direction, and then increase in magnitude toward the next solstice. One can see in Fig. 2 that there is a gradual "seesaw" effect produced by the movement of helium in the thermosphere throughout the year.

The effects of a variation in the eddy diffusion coefficient and a changing homopause altitude on the distribution of helium as an explanation for the winter helium enhancement, has been considered by Kockarts (1972). He shows that these mechanisms alone cannot explain the large pole to pole ratios in helium concentration that have been obtained from satellite data (see Table 1). The observed latitudinal distribution of helium is difficult to explain without invoking thermospheric winds.

The $A E$-D helium concentration measurements used to investigate the altitude dependence of the latitudinal distribution of helium are presented in Fig. 5. These data imply there is upwelling occurring near the winter pole. If only the winter helium bulge at all altitudes was represented in Fig. 5, all contours would slope from lower left toward upper right in the figure. This is true for higher altitudes; however, for the lower altitudes near the winter pole (lower right corner of Fig. 5), the contours turn sharply downward. This indicates that the helium number density is depressed in this region and the latitude of the peak in the helium enhancement varies with altitude. It is logical to assume that the forcing for this depletion of helium is vertical motion caused by auroral heating which carries helium out of the auroral zone. Such vertical motion has been postulated by Hays et al.(1973), and Mayr et al. (1978). The same effect is not seen at the summer pole because vertical motion induced by auroral heating is masked by the larger scale circulation pattern, which drives helium from summer to winter pole (Mayr et al., 1978). Clearly the thermospheric dynamical system cannot be described simply by a global pole to pole circulation which excludes the dynamics of the auroral zone.

Several investigators have studied the distribution of helium in the thermosphere (see Table 1). The most commonly used parameter for comparison of these results is the ratio of the helium number densities at winter and summer poles at solstice which, in general, is taken to be the ratio of the maximum to minimum value of helium number density. The $A E-C$ data presented in this paper yield a maximum to minimum helium number density ratio of 24 for December 1974 (F10.7 $=86.8)$ and 33 for June $1975(\mathrm{~F} 10.7=68.5)$, for the Northern Hemisphere winter and summer solstices, respectively. These values do not agree in all cases with those of other investigators (see Table 1). We believe that the most significant factor in the apparent disagreement among investigators as to pole to pole ratios is the effect of the solar cycle on the helium distribution. The greater the solar activity, the smaller the helium pole to pole ratio tends to be. This may be 
TABLE 1. REPORTED HELIUM POLE TO POLE RATIOS

\begin{tabular}{|c|c|c|c|c|c|}
\hline References & $\begin{array}{c}\text { Date of } \\
\text { measurement }\end{array}$ & $\begin{array}{l}\text { Satellite and } \\
\text { orbital } \\
\text { inclination } \\
(9)\end{array}$ & $\begin{array}{l}\text { Altitude } \\
(\mathrm{km})\end{array}$ & $\begin{array}{l}{[\mathrm{He}] \text { pole to }} \\
\text { pole ratio }\end{array}$ & $\begin{array}{c}\mathrm{F} 10.7 \mathrm{~cm} \\
\text { llux } \\
\left(\mathrm{cm}^{-2} \mathrm{~s}^{-1}\right)\end{array}$ \\
\hline $\begin{array}{l}\text { J. A. Reber } \\
(1971)\end{array}$ & $\begin{array}{c}\text { June } 1969 \\
\text { December } 1969\end{array}$ & $\begin{array}{l}O G O-6 \\
(82.0)\end{array}$ & 450 & $\begin{array}{l}11 \\
15\end{array}$ & 150 \\
\hline $\begin{array}{l}\text { G. M. Keating et al. } \\
(1974)\end{array}$ & June 1969 & $\begin{array}{c}O G O-6 \\
\text { (drag improved) } \\
(82.0)\end{array}$ & 450 & 21 & 150 \\
\hline $\begin{array}{l}\text { U. von Zahn et al. } \\
\text { (1973) }\end{array}$ & $\begin{array}{l}\text { December } 1972 \\
\text { (North Pole) } \\
\text { and } \\
\text { February } 1973 \\
\text { (South Pole) }\end{array}$ & $\begin{array}{l}\text { ESRO-4 } \\
(91.0)\end{array}$ & 270 & 20 & 105 \\
\hline $\begin{array}{l}\text { K. Mauersberger et al. } \\
\text { (1976a) }\end{array}$ & $\begin{array}{c}\text { February } 1974 \\
\text { (North Pole) } \\
\text { and } \\
\text { June } 1974 \\
\text { (North Pole) }\end{array}$ & $\begin{array}{l}A E-C \\
(68.1)\end{array}$ & 275 & 25 & 80 \\
\hline $\begin{array}{l}\text { R. P. Cageao and } \\
\text { R. B. Kerr (this paper) }\end{array}$ & $\begin{array}{c}\text { June } 1975 \\
\text { December } 1974\end{array}$ & $\begin{array}{l}A E-\mathrm{C} \\
(68.1)\end{array}$ & 275 & $\begin{array}{l}33 \\
24\end{array}$ & $\begin{array}{l}67 \\
89\end{array}$ \\
\hline $\begin{array}{l}\text { K. Mauersberger et al. } \\
(1976 b)\end{array}$ & December 1975 & $\begin{array}{l}A E-\mathrm{D} \\
(90.2)\end{array}$ & 500 & 20 & $<80$ \\
\hline
\end{tabular}

due to increased winds out of the solar regions during periods of increased solar activity. These increased winds were predicted by Reber and Hays (1973).

\section{CONCLUSIONS}

It was found, using measurements from $A E-C$, that the average helium latitudinal distribution in the thermosphere changes in a smooth, continuous manner from month to month.

The maximum pole to pole ratio observed was 33 in June 1975 when solar activity was at a minimum. The maximum concentration of helium was found near the winter pole, but it was noted that auroral heating alters the location of this peak in latitude depending on the altitude of observation.

Further studies of thermospheric dynamics are needed to better explain the distribution of helium in the Earth's thermosphere and the way this distribution changes with time. The data presented here shows a slow redistribution of helium in the upper atmosphere, indicating that mean thermospheric winds vary slowly in magnitude. The distribution of helium at the poles indicates that auroral dynamics should be included to better approximate the total thermospheric wind systems, particularly at the lower altitudes.

Helium, as a tracer gas, can provide valuable information for the determination of the general circulation patterns in the thermosphere. Continued helium measurements over the next few solar cycles would serve to improve our understanding of the effects of solar and geomagnetic activity on thermospheric dynamics.

Acknowledyments - The authors would like to thank Prof. Paul B. Hays for helpful comments and also Dr. V.J. Abreu, R. G. Burnside and S. Solomon of the University of Michigan for their assistance in data acquisition and reduction. This work was made possible through the availability of an aeronomy data base at the University of Michigan provided under NASA grants NAS5-23006 and NAGW-496. This research was begun in the Thermosphere and lonosphere course of the Atmospheric and Oceanic Science Department at the University of Michigan.

\section{REFERENCES}

Dalgarno, A., Hanson, W. B., Spencer, N. W. and Schmerling, E. R. (1973) The Atmosphere Explorer mission. Radio Sci.8, 263.

Hays, P. B.,Jones, R. A. and Rees, M. H.(1973) Auroral heating and the composition of the neutral atmosphere. Planet. Space Sei. 21, 559 .

Hedin, A. E. (1983) A revised thermospheric model based on mass spectrometer and incoherent scatter data: MSIS-83. J. geophys. Res. 88, 10170.

Hedin, A. E., Salah, J. E., Evans, J. V., Reber, C. A., Newton, G. P., Spencer, N. W., Kayser, D. C., Alcayde, D., Baner, P., 
Cogger, L. and McClure, J. P. (1977) A global thermospheric model based on mass spectrometer and incoherent scatter data, MSIS 1, $\mathrm{N}_{2}$ density and temperature. J. geophys. Res. 82, 2139.

Jacchia, L. G., Slowey, J. W. and von Zahn, U. (1976) Latitudinal changes of composition in the disturbed thermosphere from ESRO 4 measurements. J.geophys. Res. 81, 36.

Keating, G. M., Prior, E. J., McDougal, D.S. and Nicholson, J. Y. (1974) A critical evaluation of the OGO 6 helium model. Paper presented at the 17th annual COSPAR meeting, Comm. on Space Res., Sao Paulo, Brazil.

Keating, G. M. and Prior, E. J.(1968) The winter helium bulge. Space Res. 8, 982.

Kockarts, G. (1972) Distribution of hydrogen and helium in the upper atmosphere. J. atmos. terr. Phys. 34, 1729.

Mauersberger, K., Kayser, D. C., Potter, W. E. and Nier, A. O. (1976a) Seasonal variation of neutral thermospheric constituents in the northern hemisphere. J.geophys. Res. 81, 7.

Manersherger, K., Potter, W. E. and Kayser, D. C. (1976b) A direct measurement of the winter helium bulge. Geophys. Res. Lett. 3, 269.

Mayr, H. G., Harris, I. and Spencer, N. W. (1978) Some properties of upper atmosphere dynamics. Rev. Geophys. Space Phys. 16, 539.

Newton, G. P., Kasprzak, W. T., Curtis, S. A. and Pelz, D. T (1975) Local lime variation of equatorial thermospheric composition determined by the San Marco 3 NACE. $J$. geophys. Res. 80, 2289.

Nier, A. O., Potter, W. E., Hickman, D. R. and Mauersberger, K. (1973) The open-source neutral-mass spectrometer on Atmosphere Explorer-C, -D, and -E. Radio Sci. 8, 271.
Pelz, D. T., Reber, C. A., Hedin, A. E. and Carignan, G. R. (1973) A neutral-atmosphere composition experiment for the Atmosphere Explorer-C, -D, and -E. Radio Sci. 8, 277.

Reber, C. A. (1976) Dynamical effects in the distribution of helium in the thermosphere. J. atmos. terr. Phys. 38, 829.

Reber, C. A. and Hays, P. B. (1973) Thermospheric wind effects on the distribution of helium and argon in the earth's upper atmosphere. J. geophys. Res. 78, 2977.

Reber, C. A., Harpold, D. N., Horowitz, R. and Hedin, A. E. (1971) Horizontal distribution of helium in the earth's upper atmosphere. J. geophys. Res. 76, 1845.

Reber, C. A., Cooley, J. E. and Harpold, D. N. (1968) Upper atmosphere hydrogen and helium measurements from the Explorer 32 satellite. Space Res. 8, 993.

Spencer, N. W., Brace, L. H. and Grimes, D. W. (1973a) The Atmosphere Explorer spacecraft system. Radio Sci. 8, 267.

Spencer, N. W., Niemann, H. B. and Carignan, G. R. (1973b) The neutral atmosphere temperature experiment. Radio Sci. $8,284$.

Trinks, H., von 7ahn, J., Reber, C...A.,Hedin, A. E., Spencer, N. W., Krankowsky, D., Lammerzahl, P., Kayser, D. C. and Nier, A. O. (1977) Intercomparison of neutral composition measurements from the satellites ESRO 4, AEROS A, AEROS B, and Atmosphere Explorer C.J.geophys. Res. 82, 1261.

von Zahn, U. (1975) early aeronomy results from the satellite ESRO 4, in Atmospheres of Earth and the Planets, p. 133. D. Reidel, Dordrecht.

von Zahn, U., Fricke, K. H. and Trinks, H. (1973) ESRO 4 gas analyser results 1. First observation of the summer argon bulge. J. geophys. Res. 78, 7560. 